\title{
Novel design of Multiband Slotted and Miniaturized Microstrip Patch Antenna for $\mathrm{X}$ and $\mathrm{Ku}$-band Applications
}

P. Mercy ( $\square$ arockiapackia@gmail.com )

Arul Anandar College

K. S. Joseph Wilson

Arul Anandar College

\section{Manuscript}

Keywords: Rectangular Microstrip Patch Antenna, Double F Slots, Rectangular Slots, Corner cuttings, Return Loss, VSWR, Gain, Radiation Efficiency, $\mathrm{X}$ and Ku bands

Posted Date: February 10th, 2021

DOI: https://doi.org/10.21203/rs.3.rs-202899/v1

License: (c) (i) This work is licensed under a Creative Commons Attribution 4.0 International License. Read Full License 


\section{Abstract}

This article takes a research on a novel design of a multiband slotted microstrip patch antenna. It depicts a multi ultra wideband compressed and developed antenna with double F- slots, four rectangular slots, and side corner cuttings on the patch using partial Ground. The proposed multiband microstrip patch antenna can resonate at six unique frequencies between $8 \mathrm{GHz}$ and $19 \mathrm{GHz}$ in $\mathrm{X}$ and ku bands and execute the reflected power of $-23.8351 \mathrm{~dB},-32.9380$ $\mathrm{dB},-14.6726 \mathrm{~dB},-22.2810 \mathrm{~dB},-19.0592 \mathrm{~dB}$, and $-18.8137 \mathrm{~dB}$ at $8.6181 \mathrm{GHz}, 12.3116 \mathrm{GHz}, 14.1960 \mathrm{GHz}, 15.6281$ $\mathrm{GHz}, 18.1910 \mathrm{GHz}$, and $18.9447 \mathrm{GHz}$, respectively. The gained voltage standing wave ratio (VSWR) is less than 1(0.3918). A maximum directivity and gain of $6.9104 \mathrm{~dB}$ and $6.3769 \mathrm{~dB}$ is achieved at the resonating bands. Moreover, the effectiveness of the proposed multi-band patch antenna has been verified through the radiation pattern and radiation efficiency of measured results. The low size, weight, and cost of the geometry of this antenna make it entice for Radar engineering, police radars for measuring the speed of the vehicles, for military applications, for navigation intentions, and in finding out the weather forecast and Satellite broadcast communication, space-crafts, wireless computer networks, etc.

\section{Introduction}

A milestone in wireless communication systems is the execution of the Microstrip patch antenna which is progressing to accomplish the challenging demands of the new breed of antenna technology. In present-day wireless communication systems antennas are broadly used because of their inherent proficiencies of a low profile, lightweight, consistent design, low cost, ease of fabrication, and ease of integration with circuits. Since wireless communication devices have become a crucial part of our daily communication life, the need for a low profile miniaturized multi- and wideband antennas has been developed. Communication systems that operate in the X-band are normally built engaging separate antennas for all bands. It is advisable to configure a single antenna that operates in multiple frequencies for multitasking, because it is fetching more and more essential to utilize such systems in one setting [1]. A microstrip patch antenna in its uncomplicated form comprises a radiating patch on one face of a dielectric substrate and a ground plane on the contrary. With respect to the shape, microstrip antenna patches can be usual or unusual. Common regular shapes are rectangular, square, circular, elliptic, and triangular, among others. These shapes have been generally carried out and the design approaches are well established. They are employed as consistent antennas for airplanes, cars, missiles, safeguard devices, and many other implementations. Commonly shaped antennas are more frequent, because they are easy to evaluate and normally present symmetric radiation patterns. The unevenly shaped patch antenna relates to a microstrip antenna whose patch measurement is configured to execute a specific antenna property such as compactness, wideband characteristics, and multi resonant operation [2]. The current spectrum assignment for ultra-wideband (UWB) radio communication has kindled and renewed interest in the subject of UWB antennas. Several designs have been latterly suggested for UWB antennas. However, traditional UWB antennas are "multi-narrowband" and, therefore, are not optimized to receive a single coherent signal across their entire operating bandwidth. Besides, higher-frequency cutoff performance is wanted for a UWB system to attain a better signal-tointerference ratio (SIR), with the growing demand for higher-frequency in data communications so as to bring down the interference from other indoor radio frequencies. On the other hand, the UWB antenna's performance and behavior must be stable and foreseeable over the matching band. Moreover, the denigration of escalating and contortion of the pulse, sufficient impedance matching, gain planeness and linear phase all over the entire-bandwidth are requirements of successful transmission and reception of UWB pulses. The size of the antenna, which must be retained small without compromising performance is the main another account in the design [3]. The Federal Communications Commission (FCC) systems admit the UWB wireless communication band operates at 3.1-10.6 GHz, with acutely low power ejection levels, is simply interceded with nearby communication systems such as the $3300-3600 \mathrm{MHz}$ WiMax communication system, the 5150-5820 MHz and 5720-5870 MHz WLAN system, X-band between 7250-8400 MHz, Wi-Fi between 
5470-5725 MHz and C-band between 3700-4200 MHz [4]. In [5] V. Bhanumathi and S. Swathi, has established an Inverted L-Shaped patch which is configured on the top of the substrate and a U-Slot is engraved in the infinite ground plane and it is detected to be obtaining maximum return loss $-24 \mathrm{~dB}$ at the frequency range of 5 to $8 \mathrm{GHz}$ with a compact size of $24 \times 36 \times 1.6 \mathrm{~mm}$ having altered ground structure which is determined to be appropriate for UWB applications. In [6] Kumar Gautam and et.al has been proposed Inverted L-Shaped Slotted Microstrip Patch Antenna with DGS for XBand Applications attains a return loss value of $-18.16 \mathrm{~dB}$ and $-30.55 \mathrm{~dB}$ for a frequency of $8.15 \mathrm{GHz}$ and $10.84 \mathrm{GHz}$ respectively with a compact size of $\mathrm{f} 16 \times 18.02 \times 1.6 \mathrm{~mm}$ having ground structure $16 \times 18.2 \mathrm{~mm}$ which can be applicable for UWB applications. [7] Janvi Meena and et.al have been suggested Slotted Patch Antenna with the resonating frequencies of $9.0 \mathrm{GHz}$ and $10.14 \mathrm{GHz}$ having return loss values of $-15.92 \mathrm{~dB}$ and $-14.84 \mathrm{~dB}$ respectively, with a peak gain of $7.50 \mathrm{~dB}$ and bandwidth $1.41 \mathrm{GHz}$ with a reduced size of $30 \times 30 \times 1.6 \mathrm{~mm}$ having ground structure 30 x 30 mm for X-band applications. [8] Brijesh Mishra and et.al have been introduced Gap Coupled Swastika-Shaped Patch Antenna for $X$ and Ku Band Applications which resonates in the frequency range of (10.25-12.4) GHz, (11.7413.52) $\mathrm{GHz}$, and (10.74-13.63) GHz with resonating frequencies of $11.3 \mathrm{GHz}, 12.6 \mathrm{GHz}$, and $12 \mathrm{GHz}$; peak gains of 3 $\mathrm{dBi}, 5 \mathrm{dBi}$, and $5.13 \mathrm{dBi}$; and maximum radiation efficiencies of $88.4 \%, 89.2 \%$, and $87.2 \%$, respectively with substrate dimension $20 \times 20 \times 1.6 \mathrm{~mm}$ having ground plane $20 \times 20 \mathrm{~mm}$. [9] Shahid Ullah and et.al have been presented a simple z-shaped meander monopole antenna having high efficiency and super ultra-wide bandwidth. It enhanced a wide bandwidth of $19.9 \mathrm{GHz}(2.8 \mathrm{GHz}$ to $22.7 \mathrm{GHz}$ ). The notion of transformer is utilized for finest matching in a special microstrip feeding line and is also adequate to reach wide bandwidth with substrate dimensions $38 \times 35 \times 1.57 \mathrm{~mm}$. Microstrip Patch Antenna (MPA) employing hybrid fractal slot (Koch-Minkowski and Koch-Koch) along with partial ground plane for wideband applications. The deficiency of these above antenna review holds that the size of the ground plane and thickness of the substrate is wide and therefore antenna loss turns high and radiation efficiency becomes less. To reduce the antenna's loss and enhance the radiation efficiency is carried out by the reduction of the size of an antenna not only in the patch but also in the ground. Our paper is designed based on this idea and the simulation results show the best enhancement in radiation efficiency and lower in return loss with multi band with respect to the above analysis. The main focus being reduction and enhancement of radiation efficiency with multi-band which causes multi- task. In our novel antenna, different approaches at size reduction in the patch have been proposed such as placing double $\mathrm{F}$ shapes and four rectangular slots in the bottom of the patch and also having cuts on the corner of the patch left and right sides to workout multiband functions. The simulated and improved outcomes are weighed up in terms of return loss, VSWR, Gain, Directivity, and radiation efficiency. The benefit of this approach is that the return loss of the antenna gets reduced, and the radiation efficiency of the antenna gets enhanced with multi-bands. The statistical study of various antenna design variables is carried out to achieve optimum Radar and Satellite applications.

\section{Antenna Design And Theory}

The proposed antenna is possessed of a double F-Slotted patch with four rectangular slots in the bottom of the patch, cuts at left and right corners of the patch and it is fed with the microstrip line to attain 50-ohm impedance for better impedance suit. Substrate FR4-epoxy of dielectric constant 4.4 has been selected for this proposal. The height of the substrate is $h=1.43 \mathrm{~mm}$.

The length and width of the substrate (Ls $\times W s$ ) are $40 \mathrm{~mm} \times 26 \mathrm{~mm}$. Measurements of the partial ground plane $(\mathrm{Lg} \times \mathrm{Wg})$ is $16.2 \mathrm{~mm} \times 12.12 \mathrm{~mm}$. Diverse specifications surveyed for this novel design are designated below in table 1 .

The antenna design is configured with double F slots having a partial Ground to encounter the essentials for the Radar and ku band implementation. This antenna has a wideband operating in the frequency range of 8-19 GHz. 
A rectangular microstrip patch antenna is presented with novel deformity inserted in the patch using a partial ground plane. Fig .1(a) shows a microstrip patch antenna with the partial ground without any change in the patch. In Fig.1 (b) double F slots are combined with the radiating patch, with four rectangular slots at the bottom of the patch, two at the lower edge of the left side and two at the lower edge of the right side whose lengths and widths are upgraded to execute good consequences in antenna characteristics and preferred results. To create advances in the characteristics of the suggested antenna, additionally, two cuts at the left and right corners are made in the antenna. Figure .1(c) shows the front view of the presented antenna with a partial ground to attain X and Ku-band characteristics and to bring nearer a standard return loss and to elevate the radiation efficiency of the antenna. The upgraded proportions of all the antenna parameters are declared in Figure 1.(a), 1.(b), and 1.(c). are referred to in the table.1

Table 1. Measurements of depicted Microstrip Patch Antenna (MPA)

\begin{tabular}{|cl|}
\hline Antenna design parameters & \multicolumn{1}{c|}{$\begin{array}{c}\text { Designed Values } \\
(\mathbf{m m})\end{array}$} \\
\hline Substrate material & FR4-epoxy \\
\hline Substrate Thickness (h) & 1.43 \\
\hline Length of the substrate & 40 \\
\hline Width & 26 \\
\hline Length of the patch & 19.3 \\
\hline Width of the patch & 19.27 \\
\hline Length of the ground & 16.2 \\
\hline Width of the ground & 12.12 \\
\hline Feed length, L & 19.2 \\
\hline Feed Width, W & 3 \\
\hline Vertical Right \& Left Slot1 length & 3.14 \\
\hline Vertical Right \& Left Slot1 width & 1.1 \\
\hline Vertical Right \& Left Slot2 length & 3.91 \\
\hline Vertical Right \& Left Slot2 width & 1.1 \\
\hline
\end{tabular}

\subsection{Effects of Slots and Cuts to the Patch Shape}

In terms of return loss, VSWR, gain, directivity, radiation efficiency, various patch configurations put forwarded an antenna performance. We interpose the slots on the patch, so as to get an affirmative impact on outcomes. At various stages of design limitations, the illustrated layout model is exhibited and validated. Fig. 2(a), (b), and (c) represent the design limitations at various junctures. Above Fig. 2(a) oulinining the antenna structure that incorporates a simple patch with the partial ground without any slot inserted in it. It resonates at triple-band frequency $8.9 \mathrm{GHz}, 13.175 \mathrm{GHz}$, $17.75 \mathrm{GHz}$ with return loss of $-20.8362 \mathrm{~dB},-29.8018 \mathrm{~dB},-13.9266 \mathrm{~dB}$, with the gain of $2.9046 \mathrm{~dB}, 2.8959 \mathrm{~dB}, 4.0926 \mathrm{~dB}$ and with the radiation efficiency of $84 \%, 87 \%, 94 \%$ respectively. Also with the insertion of double F Slots in Fig2.(b), causes it to resonate in three frequency bands $8.9 \mathrm{GHz}, 13.175 \mathrm{GHz}, 17.75 \mathrm{GHz}$ with the better outcomes of return loss $-20.5978 d B,-32.5549 d B,-13.892 d B$, gain $2.6291 d B, 2.628 d B, 4.5043 d B$ and radiation efficiency $81 \%, 88 \%, 96 \%$ 
respectively. In fig 2.(c), by interposing the double F shaped slots with left and right side corner cuts and small slots in the bottom of the patch on the left and right side, the five multiple bands $8.75 \mathrm{GHz}, 12.05 \mathrm{GHz}, 13.325 \mathrm{GHz}, 15.275 \mathrm{GHz}$, $17.975 \mathrm{GHz}$ has been obtained with the return loss of $-20.6945,-11.6413,-32.518,-21.2814,-18.8097$. Finally, the two slots are included at the left and right bottom of the patch which enhances the antenna characteristics in fig.2(c) that makes it to resonate six multiple bands $8.6181 \mathrm{GHz}, 12.3116 \mathrm{GHz}, 14.1960 \mathrm{GHz}, 15.6281 \mathrm{GHz}, 18.1910 \mathrm{GHz}$, and $18.9447 \mathrm{GHz}$ with the return loss of $-23.8361 \mathrm{~dB},-32.9380 \mathrm{~dB},-146726 \mathrm{~dB},-22.2810 \mathrm{~dB},-19.0592 \mathrm{~dB},-18.8137 \mathrm{~dB}$, gain $2.97 \mathrm{~dB}, 3.89 \mathrm{~dB}, 3.06 \mathrm{~dB}, 5.34 \mathrm{~dB}, 6.02 \mathrm{~dB}, 6.37 \mathrm{~dB}$, radiation efficiency 89\%, 79\%, 84\%, 81\%, 94\%, $92 \%$ respectively.

Table.2 Proposed Micro strip Patch Antenna

\begin{tabular}{|lllllll|}
\hline Patch & $\begin{array}{l}\text { Return } \\
\text { Loss }\end{array}$ & $\begin{array}{l}\text { VSWR } \\
(\mathbf{d B})\end{array}$ & $\begin{array}{l}\text { Gain } \\
(\mathbf{d B})\end{array}$ & $\begin{array}{c}\text { Directivity } \\
(\mathrm{dB})\end{array}$ & $\begin{array}{l}\text { Resonant } \\
\text { Frequency } \\
(\mathrm{GHz})\end{array}$ & $\begin{array}{l}\text { Radiation } \\
\text { Efficiency(\%) }\end{array}$ \\
\hline $\begin{array}{l}\text { Patch with partial } \\
\text { ground }\end{array}$ & $\mathbf{- 2 0 . 8 3 6 2}$ & $\mathbf{1 . 5 8 2 1}$ & $\mathbf{2 . 9 0 4 6}$ & $\mathbf{3 . 6 1 7 3}$ & $\mathbf{8 . 9}$ & $\mathbf{8 4}$ \\
& -29.2560 & & 2.8959 & 3.4587 & 13.25 & 87 \\
\hline Double -F Slotted & -13.8835 & 0.5622 & 4.0926 & 4.3281 & 17.6 & 94 \\
& -20.5978 & $\mathbf{1 . 1 0 2 6}$ & $\mathbf{2 . 6 2 9 1}$ & $\mathbf{3 . 4 9 3 5}$ & $\mathbf{8 . 9}$ & $\mathbf{8 1}$ \\
& -32.5978 & & 2.6280 & 3.1822 & 13.17 & 88 \\
\hline Proposed design & -13.8920 & & 4.5043 & 4.6444 & 17.75 & 96 \\
& -23.8351 & $\mathbf{1 . 1 1 8 6}$ & $\mathbf{2 . 9 7 5 7}$ & $\mathbf{3 . 3 3 0 7}$ & $\mathbf{8 . 6 1 8 1}$ & $\mathbf{8 9}$ \\
& -32.9380 & 0.3918 & 3.8395 & 4.8116 & 12.3116 & 79 \\
& -14.6726 & & 3.0622 & 3.6372 & 14.1960 & 84 \\
& -22.2810 & 1.3854 & 5.3433 & 6.5220 & 15.628 & 81 \\
& -19.0592 & 1.9440 & 6.0244 & 6.3752 & 18.1910 & 94 \\
& -18.8137 & & 6.3769 & 6.9104 & 18.9447 & 92 \\
\hline
\end{tabular}

\section{Results And Discussion}

Figure 3, shows the correlation plots of the simulated return loss curves against frequency for various patch configurations. Return loss specifies the amount of power reflected back. The above figure ensures the course of action of the reduced patch with the partial ground which enhances the antenna to envelop an $\mathrm{X}$ and Ku-band range. To upgrade radiation efficiency by reducing the return loss of the antenna, $F$ shapes and rectangular slots are inserted in the patch which covers $X$ band $(8-12 \mathrm{GHz})$ for radar applications and ku band $(12-18 \mathrm{GHz})$ for satellite applications. Designed microstrip patch antenna characteristics are shown as follows

\subsection{Return Loss of prosed Antenna}

When simulated return loss is plotted on $\mathrm{Y}$-axis with respect to the frequency on $\mathrm{X}$-axis, Fig 4 shows that the suggested antenna reveals $X$ and Ku-band behaviors. We minimize the return loss, by interposing double F- shape, the two rectangular slots both left and right sides in the bottom of the patch and corner cuttings, which makes it to resonate six multiple bands $8.6181 \mathrm{GHz}, 12.3116 \mathrm{GHz}, 14.196 \mathrm{GHz}, 15.6281 \mathrm{GHz}, 18.1910 \mathrm{GHz}$, and $18.9447 \mathrm{GHz}$ with the return 
loss of $-23.8351,-32.9380,-14.6726,-22.2810,-19.0592$, and -18.8137 respectively. Thus, the HFSS simulation result confirms that the return loss for the aimed multiband has been attained.

\subsection{VSWR of designed antenna}

VSWR is an essential requirement for the proper function of the antenna which implies the impedance matching between the source and the feed is optimum. It depicts the pattern and behavior of the antenna. In figure 5, the VSWR investigation has been shown. The VSWR obtained at the favored multiband is 1.11 at frequency $8.61 \mathrm{GHz}, 0.39$ at frequency $12.31 \mathrm{GHz}$, and 1.33 at frequency $15.62 \mathrm{GHz}, 1.94$ at frequency $18.19 \mathrm{GHz}$ respectively. Thus, the proposed antenna is capable of providing the coveted VSWR outcomes.

\subsection{Gain of the proposed Antenna}

The power radiation in a given direction is revealed by the antenna gain. Figure 6(a), 6(b), 6(c), 6(d), 6(e), 6(f) shows the $3 \mathrm{D}$ view of the broadband gain of the designed antenna which varies with respect to the frequency. The achieved gains are $2.9757 \mathrm{~dB}, 3.8395 \mathrm{~dB}, 3.0622 \mathrm{~dB}, 5.3433 \mathrm{~dB}, 6.0244 \mathrm{~dB}, 6.3769 \mathrm{~dB}$ at the resonated multiband frequency is 8.6181 $\mathrm{GHz}, 12.3116 \mathrm{GHz}, 14.1960 \mathrm{GHz}, 15.6281 \mathrm{GHz}, 18.1910 \mathrm{GHz}$, and $18.9447 \mathrm{GHz}$ respectively. The highest attainable gain for the suggested antenna is $6.3769 \mathrm{~dB}$ at a frequency of $18.9447 \mathrm{GHz}$ which means the antenna is more efficacious at this frequency, while a low gain of $2.9757 \mathrm{~dB}$ at a resonant frequency of $8.6181 \mathrm{GHz}$ which means the antenna is lesser effective at this frequency. The designed antenna exhibits the peak gain of $6.3769 \mathrm{~dB}$ is obtained at 18.9447 GHz frequency which makes the antenna advantageous for Satellite communication applications.

\subsection{Directivity of the proposed Antenna}

Fig (7) shows the directivity of the suggested microstrip patch antenna versus frequency. The potential of an antenna that improves energy in a specific direction when transmitting energy better from a particular direction when receiving such as reveling by directivity. It exhibits $3.3307 \mathrm{~dB}, 4.8116 \mathrm{~dB}, 3.6372 \mathrm{~dB}, 6.5220 \mathrm{~dB}, 6.3752 \mathrm{~dB}$, and $6.9104 \mathrm{~dB}$ at the resonated multiband frequency of $8.6181 \mathrm{GHz}, 12.3116 \mathrm{GHz}, 14.1960 \mathrm{GHz}, 15.6281 \mathrm{GHz}, 18.1910 \mathrm{GHz}$, and 18.9447 $\mathrm{GHz}$ respectively. We come to know from the directivity plot that the maximum amount of radiation intensity which is equivalent to $6.9104 \mathrm{~dB}$ is attained at a resonant frequency of $18.9447 \mathrm{GHz}$. Table (4) which is given below reveals the Return loss, VSWR Gain, Directivity, and radiation efficiency for different resonant frequencies of the proposed antenna

Table (4) presents the characteristics of the proposed microstrip patch antenna.

\begin{tabular}{|llllll|}
\hline Resonance frequency $(\mathrm{GHz})$ & Return Loss $(\mathrm{dB})$ & VSWR & Gain(dB) & Directivity(dB) & Radiation efficiency (\%) \\
\hline 8.6181 & -23.8361 & 1.1186 & 2.9757 & 3.3307 & 89 \\
\hline 12.31116 & -32.9380 & 0.3918 & 3.8395 & 4.8116 & 79 \\
\hline 14.1960 & -14.6726 & & 3.0622 & 3.6372 & 84 \\
\hline 15.6281 & -22.2810 & 1.3386 & 5.3433 & 6.5220 & 81 \\
\hline 18.1910 & -19.0592 & 1.9440 & 6.0244 & 6.3752 & 94 \\
\hline 18.9447 & -18.8137 & & 6.3769 & 6.9104 & 92 \\
\hline
\end{tabular}

\subsection{Radiation Pattern}

The 3D radiation patterns for the elevation and azimuthal plane respectively of the proposed antenna is illustrated in figures above. The radiation pattern indicates the graphical portrayal of the radiation properties of the antenna as a 
function of space. The radiation pattern reports how an antenna causes energy radiation into space and reception.

Table. (5) Comparison of performance of the antenna introduced in previous literature's with the existing work

\begin{tabular}{|c|c|c|c|c|c|c|c|c|}
\hline $\begin{array}{l}\text { Published } \\
\text { Antenna }\end{array}$ & $\begin{array}{l}\text { Antenna } \\
\text { size } \\
(\mathrm{mm})\end{array}$ & $\begin{array}{l}\text { Height } \\
\text { (mm) }\end{array}$ & $\begin{array}{l}\text { Ground } \\
(\mathrm{mm})\end{array}$ & $\begin{array}{l}\text { Return } \\
\text { Loss } \\
\text { (dB) }\end{array}$ & $\begin{array}{l}\text { Maximum } \\
\text { Gain } \\
(\mathrm{dB})\end{array}$ & $\begin{array}{l}\text { Resonant } \\
\text { Freq } \\
\text { [GHz] }\end{array}$ & $\begin{array}{l}\text { Radiation } \\
\text { Efficiency\% }\end{array}$ & Applications \\
\hline \multirow[t]{3}{*}{ Ref.[5] } & \multirow[t]{3}{*}{$24 \times 36$} & \multirow[t]{3}{*}{1.6} & \multirow[t]{3}{*}{$24 \times 20$} & -21.7911 & \multirow[t]{3}{*}{3.01} & 4.92 & \multirow[t]{3}{*}{-} & \multirow[t]{3}{*}{ UWB band } \\
\hline & & & & -33.6083 & & 4.99 & & \\
\hline & & & & -23.0760 & & 5.02 & & \\
\hline \multirow[t]{2}{*}{ Ref.[6] } & \multirow[t]{2}{*}{$30 \times 30$} & \multirow[t]{2}{*}{1.6} & \multirow[t]{2}{*}{$30 \times 30$} & -26.85 & \multirow[t]{2}{*}{6.27} & 9 & \multirow[t]{2}{*}{-} & \multirow[t]{2}{*}{$\mathrm{X}$ band } \\
\hline & & & & -16.13 & & 10.35 & & \\
\hline \multirow[t]{2}{*}{ Ref.[7] } & \multirow[t]{2}{*}{$30 \times 30$} & \multirow[t]{2}{*}{1.6} & \multirow[t]{2}{*}{$30 \times 30$} & -15.92 & \multirow[t]{2}{*}{7.5} & 9 & \multirow[t]{2}{*}{-} & \multirow[t]{2}{*}{$\mathrm{X}$ band } \\
\hline & & & & -14.84 & & 10.14 & & \\
\hline \multirow[t]{3}{*}{ Ref.[8] } & \multirow[t]{3}{*}{$20 \times 20$} & \multirow[t]{3}{*}{1.6} & \multirow[t]{3}{*}{$20 \times 20$} & -23 & \multirow[t]{3}{*}{5.13} & 11.3 & \multirow[t]{3}{*}{89.2} & \multirow{3}{*}{$\begin{array}{l}\mathrm{X} \text { and } \mathrm{Ku} \\
\text { bands }\end{array}$} \\
\hline & & & & -14 & & 12.6 & & \\
\hline & & & & -13 & & 12 & & \\
\hline \multirow[t]{4}{*}{ Ref.[9] } & \multirow[t]{4}{*}{$38 \times 35$} & \multirow[t]{4}{*}{1.57} & \multirow[t]{4}{*}{$34 \times 34$} & -38 & \multirow[t]{4}{*}{6.4} & 5.5 & \multirow[t]{4}{*}{93} & $\begin{array}{l}\mathrm{X} \text { and ku } \\
\text { bands }\end{array}$ \\
\hline & & & & -19 & & 8.5 & & \\
\hline & & & & -16 & & 12.5 & & \\
\hline & & & & -12 & & 20 & & \\
\hline Proposed & $40 \times 26$ & 1.43 & $16.2 \times 12.12$ & -23.83 & 6.37 & 8.61 & 94 & $X$ and ku \\
\hline & & & & -32.93 & & 12.31 & & \\
\hline & & & & -14.67 & & 14.19 & & \\
\hline & & & & -22.28 & & 15.62 & & \\
\hline & & & & -19.05 & & 18.19 & & \\
\hline & & & & -18.81 & & 18.94 & & \\
\hline
\end{tabular}

From the above table (5), we come to know that the proposed antenna has similar characteristics which are as per with the already suggested antenna's. Based on the popular microstrip antenna parameters such as size, resonant frequencies, return loss, and radiation efficiency, a fair comparative analysis is presented with the other considered antennas. The antenna performance lies in the $\mathrm{X}$ and ku frequency band.

The main focus of our designed antenna is to achieve "Size reduced", "multiband resonant frequencies" and hence can be taken up for multi commercial purposes. This antenna has been profitably executed after numerous modeling and simulations by Ansoft HFSS 13.0 software to get the best solution of the parameters for overall performance. After getting good results from the simulated and measured parameters, the target was achieved. 
In this research work, with the insertion of the slots, the effective patch size is marginally reduced but the performance of an antenna is significantly improved which causes multi-band resonant frequencies, very less return loss, and excellent radiation efficiency. The proposed compact rectangular microstrip patch antenna designed with double $\mathrm{F}$ Slots, four rectangular slots, side cuttings, and partial ground which covers multiple frequencies range between $8 \mathrm{GHz}$ and $19 \mathrm{GHz}$ which is found to be suitable for $X$ and ku band applications. It is more efficient which achieves $96 \%$ efficiency. Due to the high radiation efficiency, ultra-wideband (UWB), reasonable gain, stable radiation pattern, less return loss ensures that the proposed antenna could be more suitable for radar, microwave imaging, satellite wireless communication applications and etc.

\section{Declarations}

\section{*Funding}

Not Applicable

\section{*Conflicts of interest/Competing interests}

Not Applicable

\section{Availability of data and material (data transparency)}

Not Applicable

\section{*Code availability (software application or custom code)}

Not Applicable

*Authors' contributions (optional: please review the submission guidelines from the journal whether statements are mandatory)

Not Applicable

\section{References}

[1] M. Samsuzzaman and M. T. Islam, "Inverted S-Shaped Compact Antenna for X-Band Applications", The Scientific World Journal, Vol. 2014, pp.11, 2014.

[2] A. R. Ramirez and J. C. A. Santos, "Design, Simulation, and Optimization of an Irregularly Shaped Microstrip Patch Antenna for Air-to-Ground Communications”, International Journal of Antennas and Propagation, Vol. 2017, pp. 9, 2017.

[3] M.A. Matin*, B.S. Sharif, C.C.Tsimenidis, "Microstrip patch antenna with matching slots for UWB Communications”, International Journal of Electronics and Communications, vol.61, pp.132-134, 2007.

[4] Chandraveer Singh, Gaurav Kumawat, "A Compact Rectangular Ultra-Wideband Microstrip Patch Antenna with Double Band Notch Feature at Wi-Max and WLAN”, Wireless Personal Communications, vol.114, pp. 2063-2077, 2020.

[5] V. Bhanumathi and S. Swathi, “Bandwidth Enhanced Microstrip Patch Antenna for UWB Applications”, ICTACT Journal on Microelectronics, Vol. 04, 2019. 
[6] Kumar Gautam, Janvi Meena, Praveen K Sharma, “Design and Performance Analysis of Microstrip Slot Antenna for X-Band Applications”, International Journal of Research In Electronics And Computer Engineering, Vol. 7, 2019.

[6] Ambresh P. Ambalgi, P. Naveen Kumar \& Rajendra Patil, "Simulation and practical study of L and inverted L slot Heptaband Rectangular Microstrip Antenna-notch and Characteristics, International Journal of Information Technology,vol. 12, pp.1037-1042, 2020.

[7] Janvi Meena \& Kumar Gautam \& Praveen K Sharma1, "Slotted Patch Antenna for X-Band Applications", IJRARInternational Journal of Research and Analytical Reviews, Vol.6, 2019.

[8] Brijesh Mishra, Vivek Singh and Rajeev Singh, "Gap Coupled Swastika-Shaped Patch Antenna for X and Ku Band Applications", Optical and Wireless Technologies, pp. 449-455, 2020.

[9] Shahid Ullah , Cunjun Ruan , Muhammad Shahzad Sadiq , Tanveer Ul Haq and Wenlong He, "High Efficient and Ultra Wide Band Monopole Antenna for Microwave Imaging and Communication Applications", Sensors, vol.115, 2019.

\section{Figures}

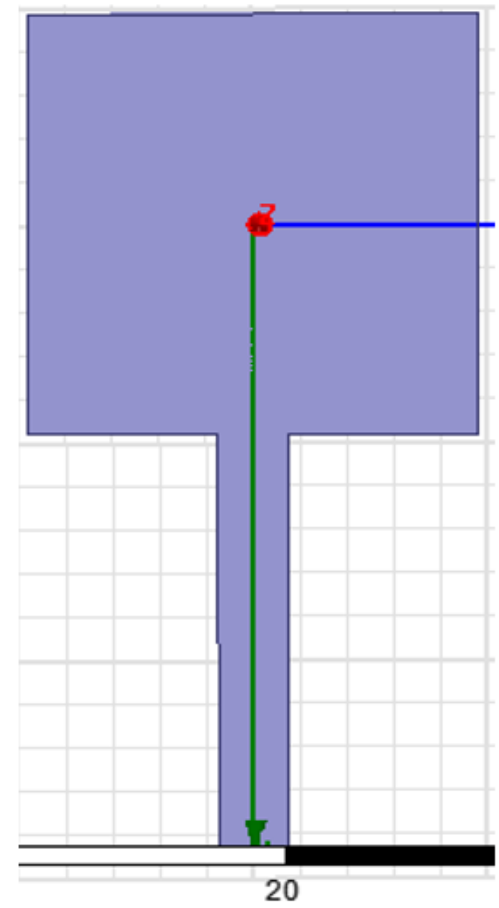

(a)

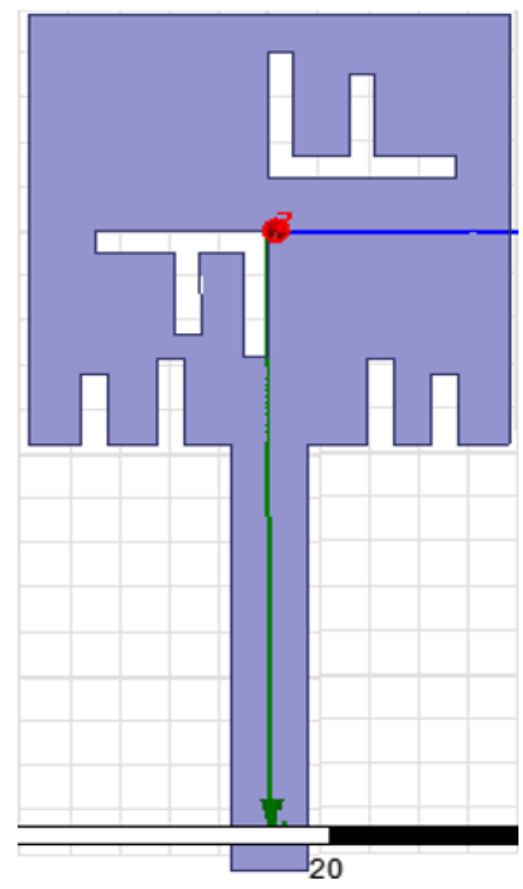

(b)

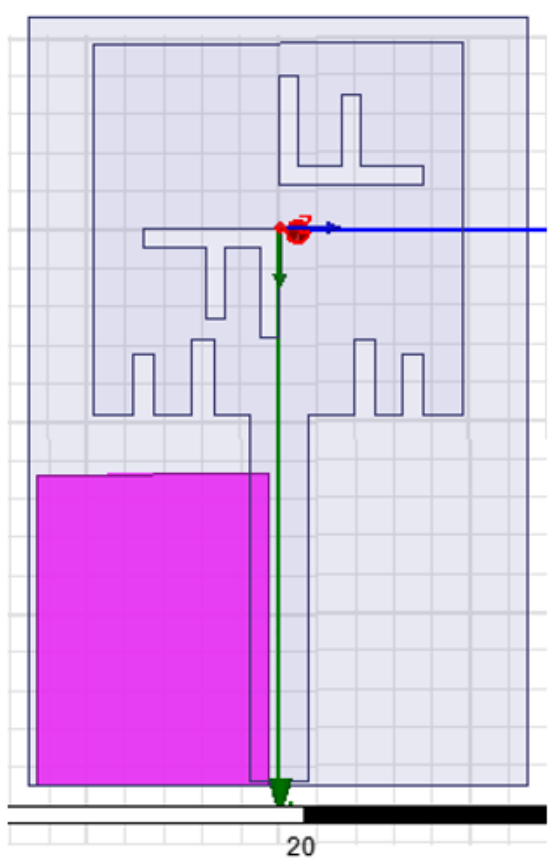

(c)

\section{Figure 1}

Antenna Geometry (a) Microstrip patch without modifications (b) Microstrip Patch with modifications (c) Final design with partial ground 


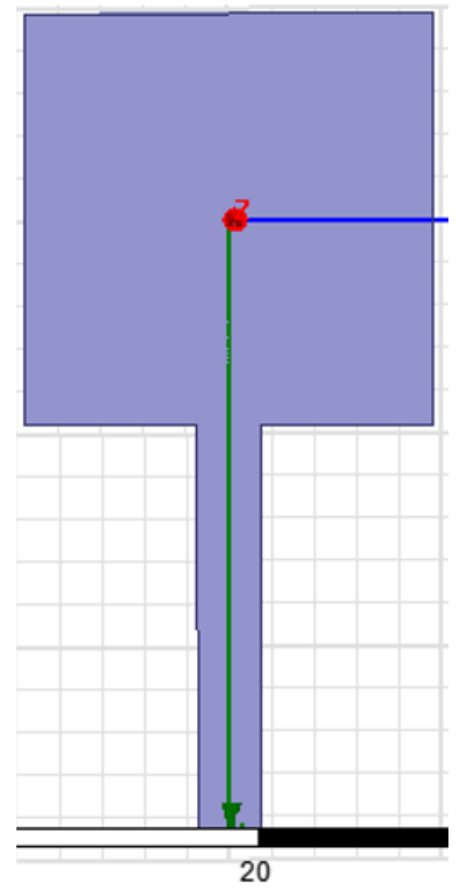

(a)

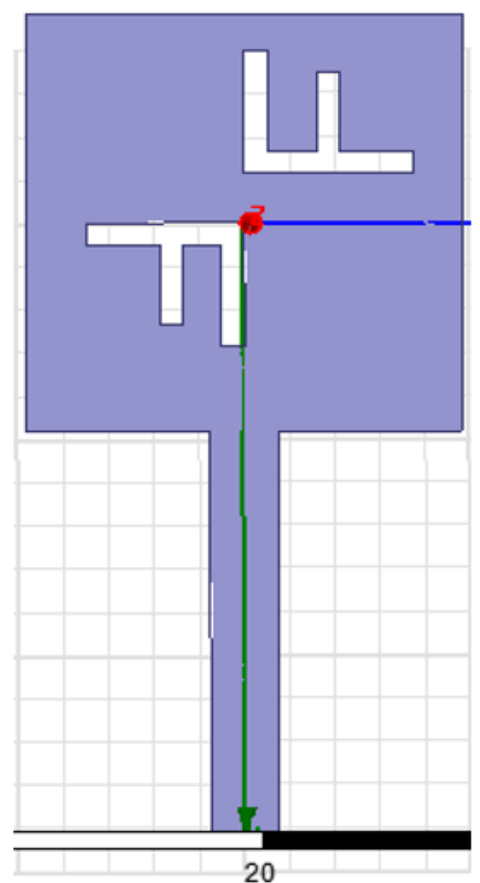

(b)

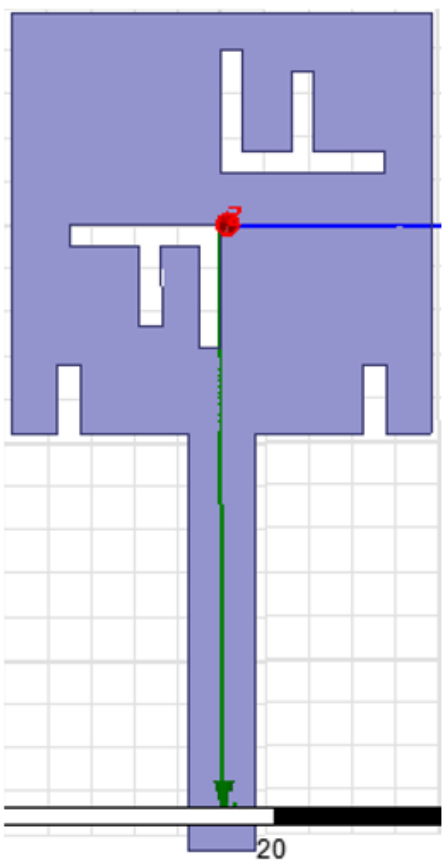

(c)

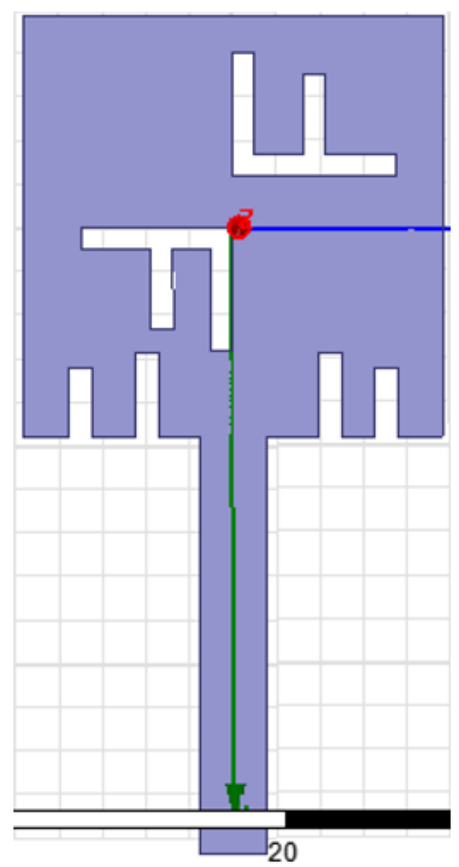

(d)

Figure 2

Antenna Modification (a) Simple patch with partial ground (b) Double F-Slots Interposed (c) Interposition of double FSlots with Corner cuttings and Single slots at right and left side (d) Proposed antenna 


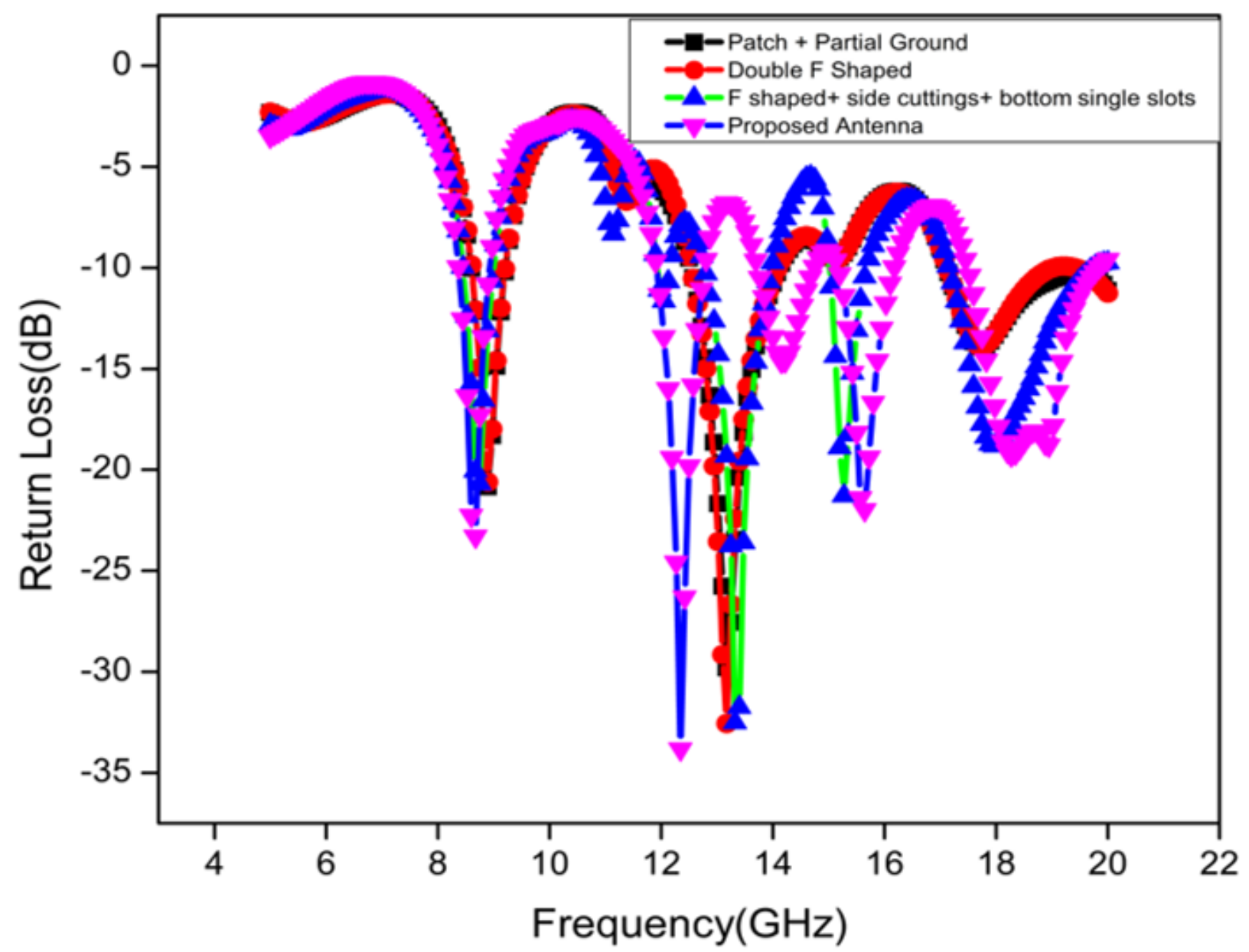

Figure 3

Return curves for different patch geometries.

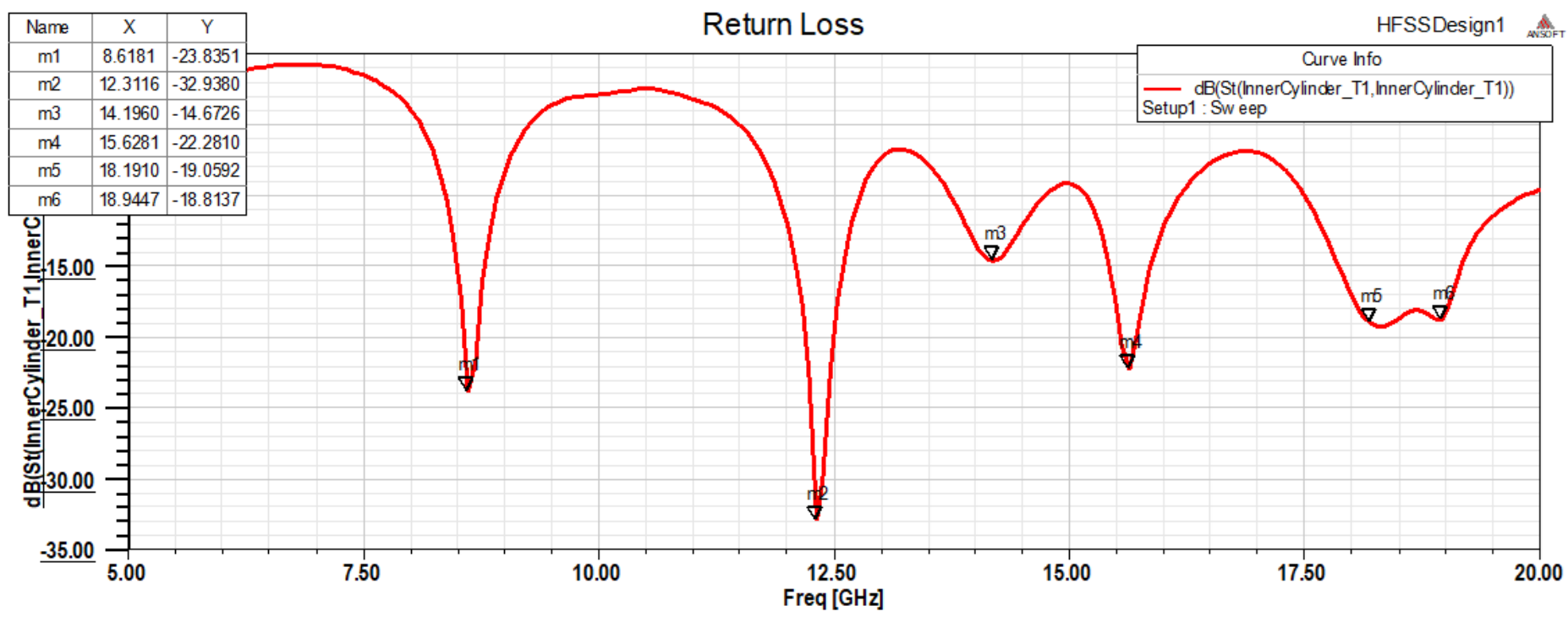

Figure 4

Graph showing Return Loss Vs Frequency 


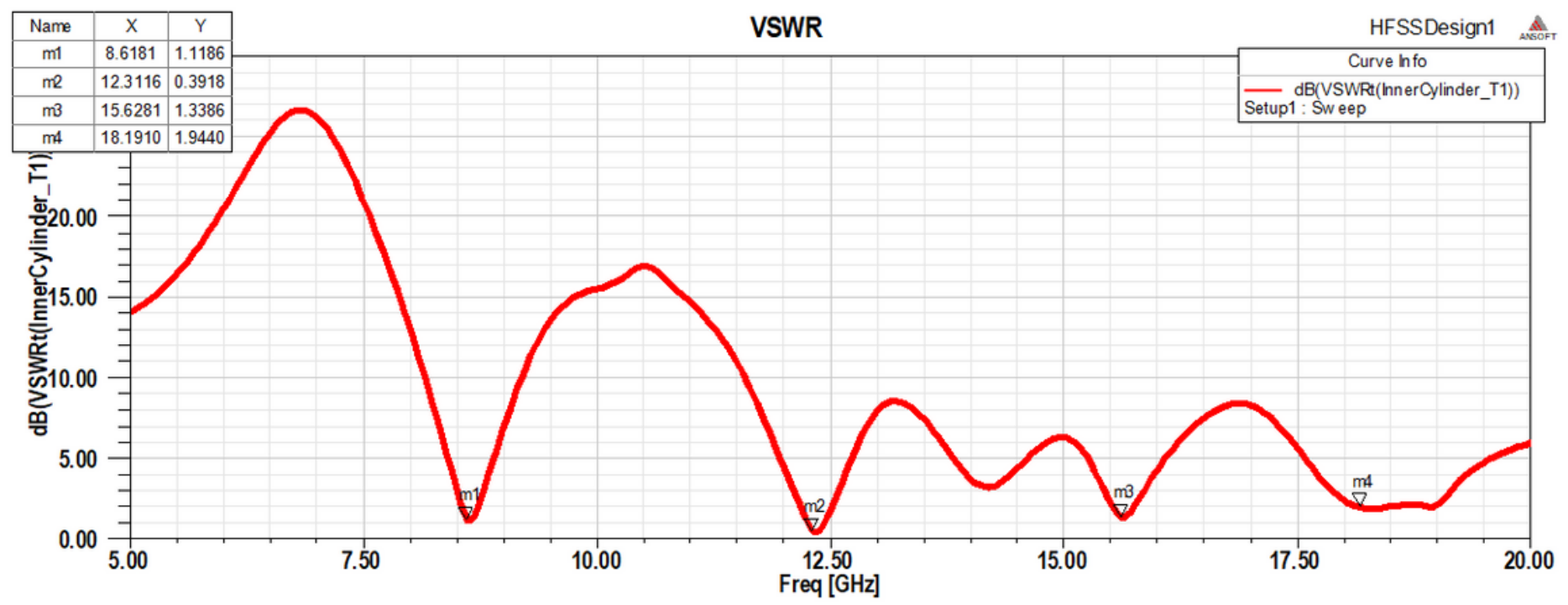

Figure 5

Graph showing VSWR Vs frequency 


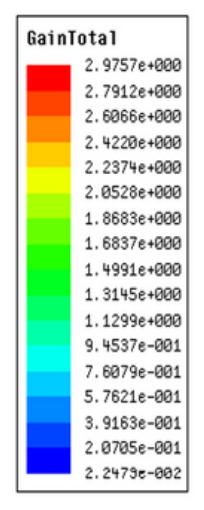

(a)

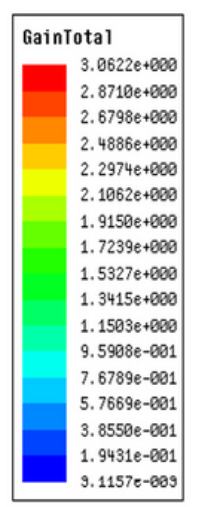

(c)

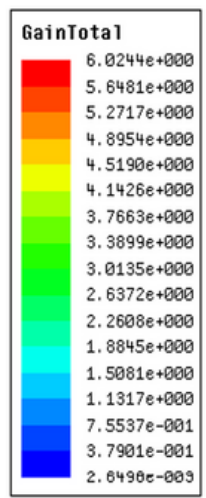

(e)
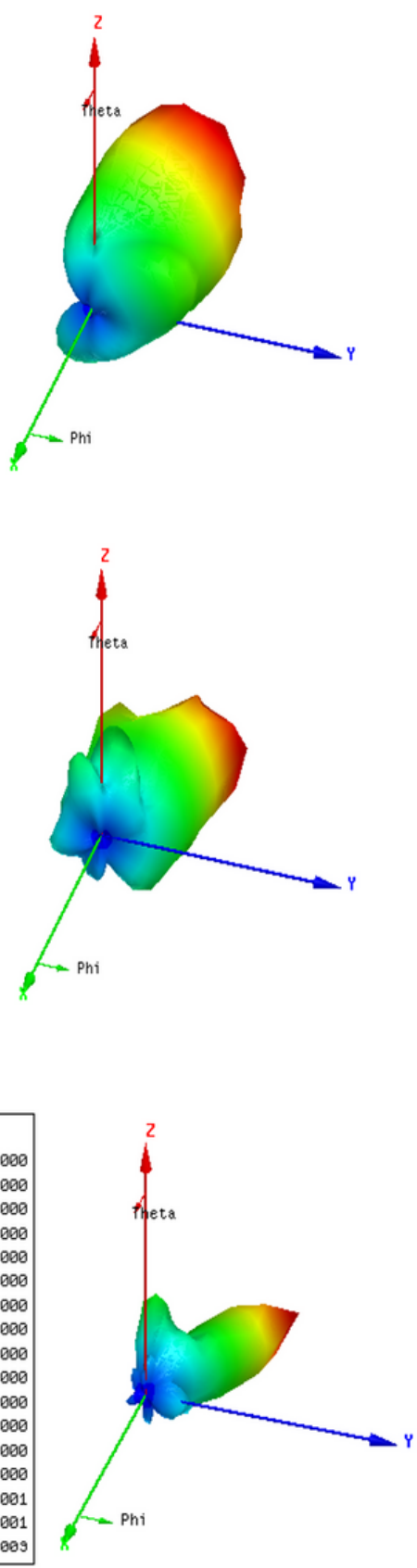

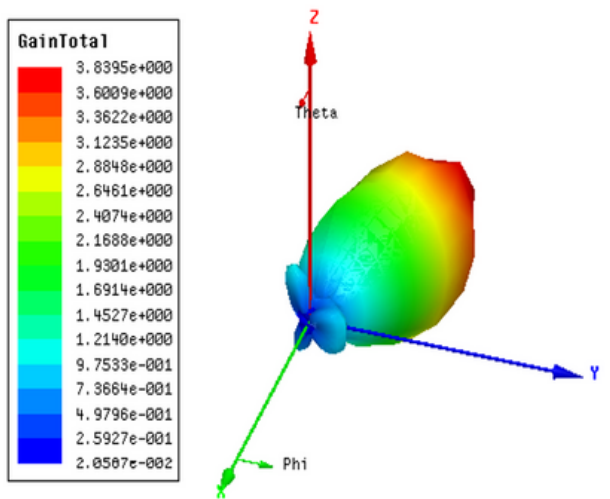

(b)

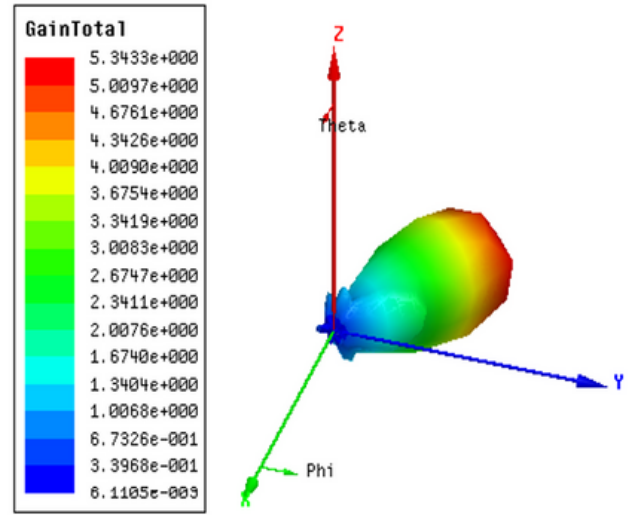

(d)

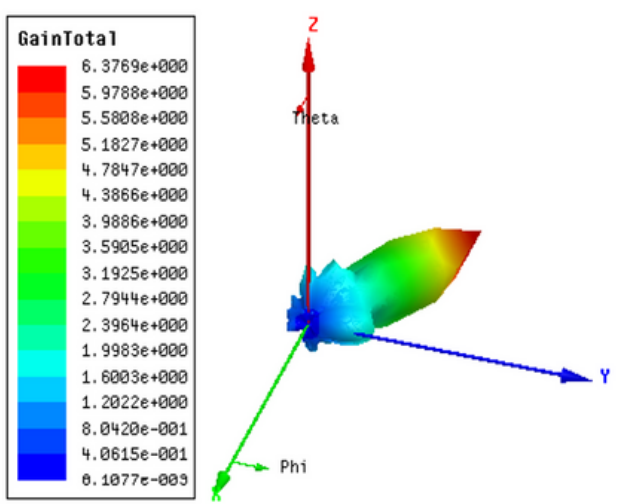

(f)

\section{Figure 6}

(a) Gain of proposed antenna at $8.6181 \mathrm{GHz}$ (b) Gain of proposed antenna at $12.3116 \mathrm{GHz}$ (c) Gain of proposed antenna at $14.1960 \mathrm{GHz}$ (d) Gain of proposed antenna at $15.6281 \mathrm{GHz}$ (e) Gain of proposed antenna at $18.1910 \mathrm{GHz}$ (f) Gain of proposed antenna at $18.9447 \mathrm{GHz}$ 


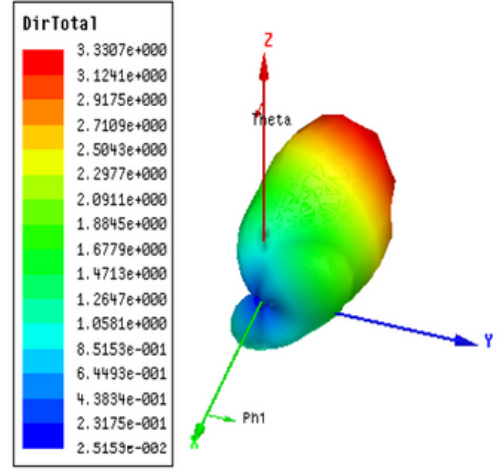

(a)

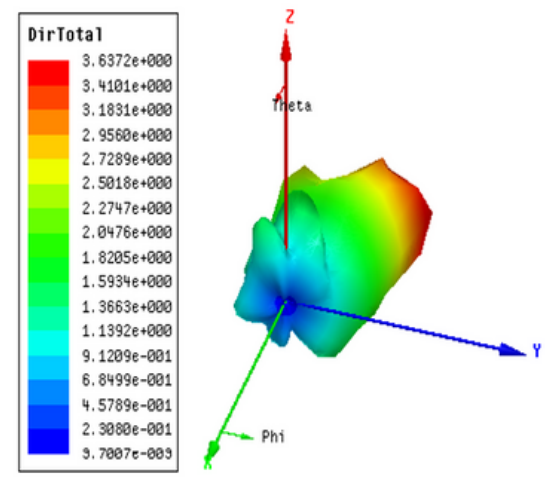

(c)

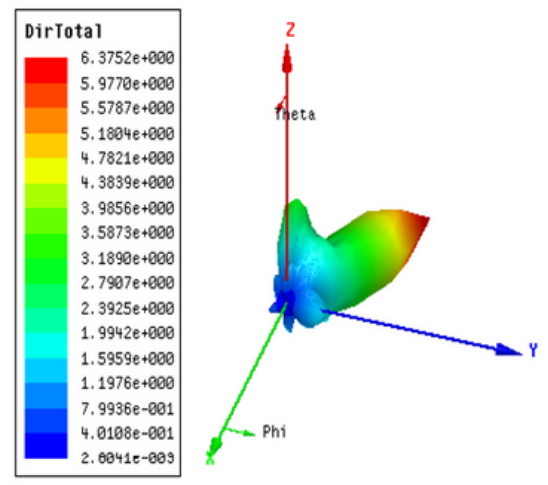

(e)

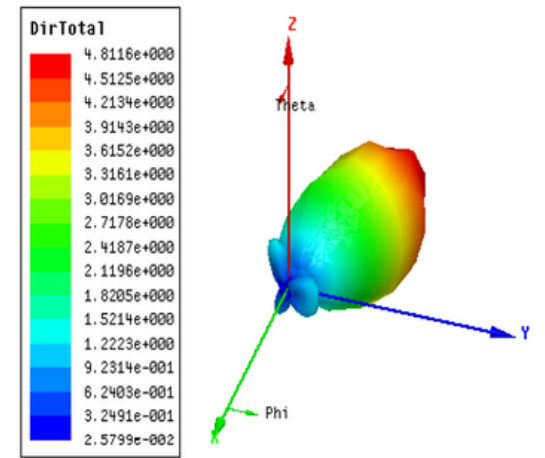

(b)

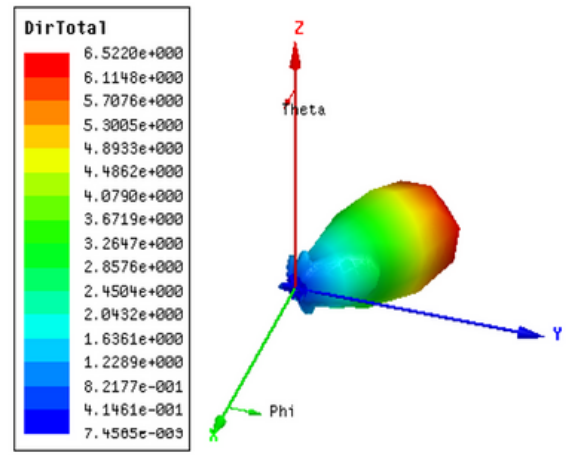

(d)

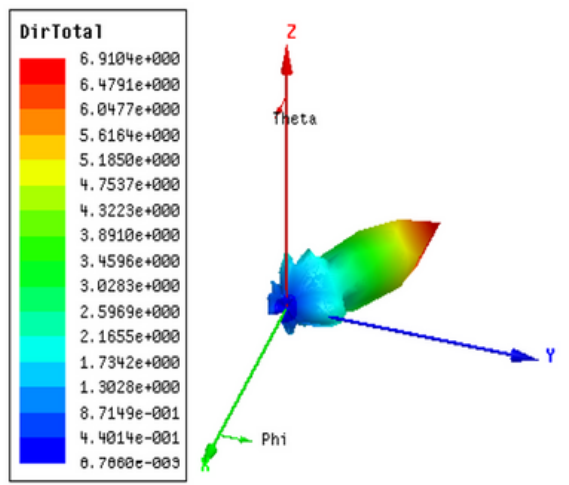

(f)

\section{Figure 7}

Graph showing Directivity of the proposed microstrip patch antenna (a) at $8.6181 \mathrm{GHz}$ (b) at $12.3116 \mathrm{GHz}$ (c) at $14.1960 \mathrm{GHz}$ (d) at $15.6281 \mathrm{GHz}$ (e) at $18.1910 \mathrm{GHz}$ (f) at $18.9447 \mathrm{GH}$ 


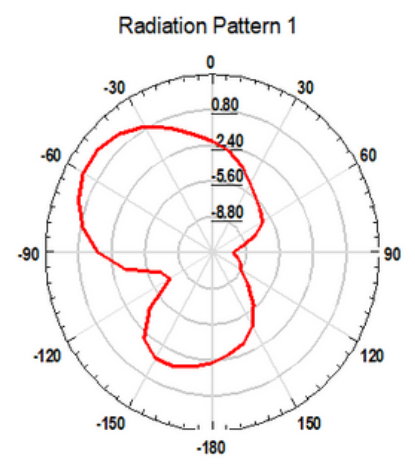

(a)

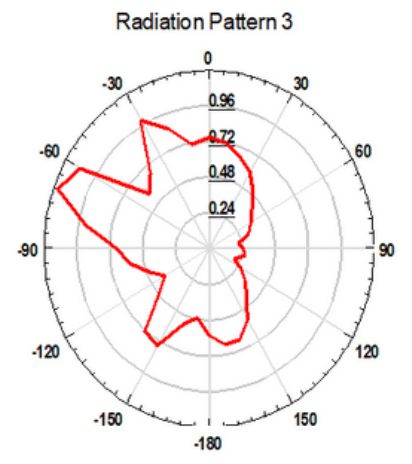

(c)

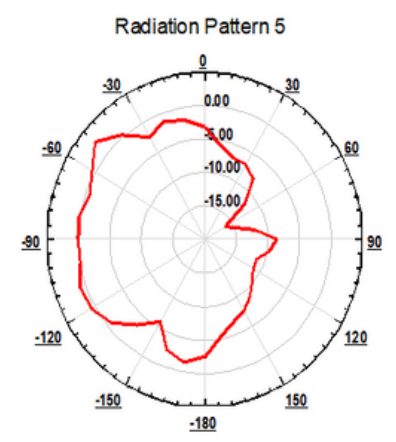

(e)
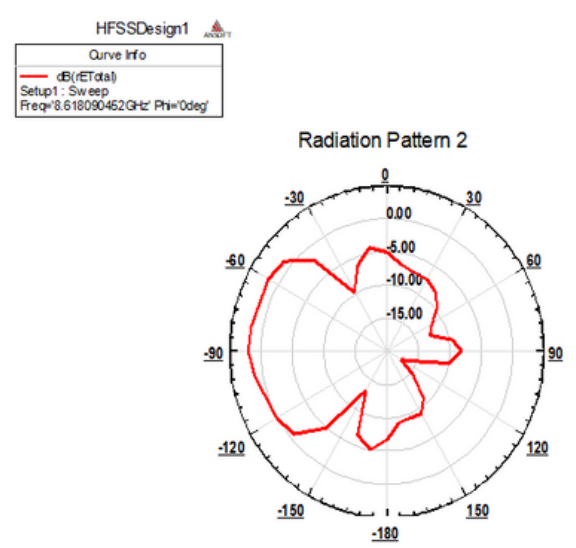

(b)
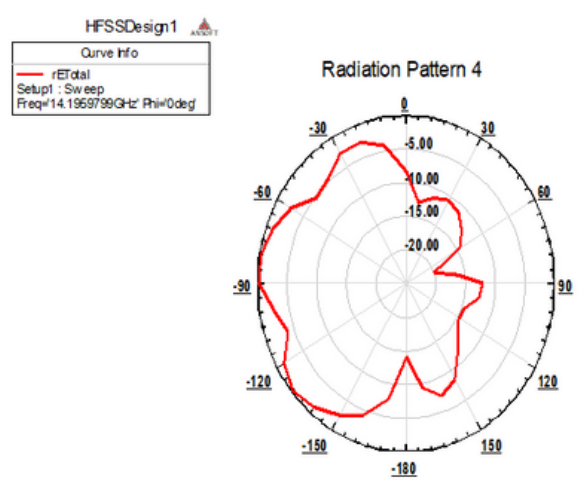

(d)
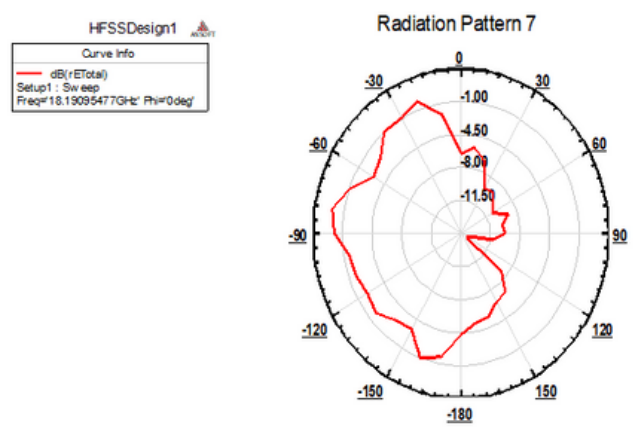

(f)
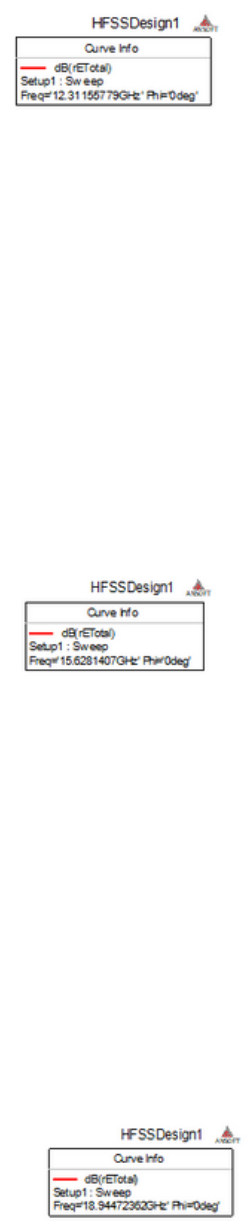

\section{Figure 8}

Radiation pattern in 3D of proposed patch antenna, (a) At $8.6181 \mathrm{GHz}$, (b) At $12.3116 \mathrm{GHz}$, (c) At $14.196 \mathrm{GHz}$, (d) At $15.6281 \mathrm{GHz}$, (e) At $18.1910 \mathrm{GHz}$, (f) At $18.9447 \mathrm{GHz}$. 